\title{
A Transmissão Psíquica na Poética Familiar de Almodóvar - Volver (2006) e Tudo sobre Minha Mãe (1999) ${ }^{1}$
}

\author{
Fabio Scorsolini-Comin ${ }^{2}$ \\ Universidade Federal do Triângulo Mineiro \\ Manoel Antônio dos Santos \\ Universidade de São Paulo
}

\begin{abstract}
RESUMO - O objetivo deste estudo é discutir de que modo a transmissão psíquica transgeracional está presente em duas obras do cineasta Pedro Almodóvar: Volver (2006) e Tudo sobre minha mãe (1999). Tais obras mantêm uma intertextualidade ao destacarem histórias de mulheres que sofrem em seus casamentos pela traição ou pelas mudanças comportamentais/identitárias de seus maridos. Ambos os filmes apresentam como eixo narrativo a produção de mentiras que são contadas pelas protagonistas e que escamoteiam suas identidades e suas próprias histórias que, de certo modo, remontam às de suas mães. Tais trajetórias são repetidas inconscientemente como forma não apenas de sobrevivência e de preservação de elementos psíquicos, como também para elaborar dramas pessoais, tragédias humanas e escolhas amorosas tidas como equivocadas.
\end{abstract}

Palavras-chave: transmissão psíquica, família, relações conjugais, cinema, psicanálise

\section{The Psychic Transmission in Movies of Almodóvar's - Volver (2006) and All about My Mother (1999)}

\begin{abstract}
The purpose of this paper is to discuss in which way psychic transmission between generations is present in two movies of Pedro Almodóvar: Volver - To Return (2006) and All about my mother (1999). These movies have a intertextual support in highlighting stories of women who suffered in their marriages due to infidelity or behavior changes of their husbands. Both movies present the creation of lies that are told by the protagonists and that, somehow, go back to the stories of their mothers. Such trajectories are repeated unconsciously as a means not only to survive and to preserve psychic elements, but also to develop personal dramas, human tragedies and loving choices perceived as erroneous.
\end{abstract}

Key words: psychic transmission, family, marriage relationship, cinema, psychoanalysis

Como instituição humana, a família é elemento presente em toda obra cinematográfica, revelando movimentos e interpretações distintas acerca dessa dimensão, sua constituição, seus personagens e suas dinâmicas interativas (Moellmann, 2007). Podemos afirmar, com segurança, que não há gênero de filme que não aborde, ainda que tangencialmente, alguma concepção de família. Outras obras cinematográficas, no entanto, elegem a família como pivô principal de seu enredo, desvelando não apenas concepções sobre o universo familiar, mas visões correspondentes aos elementos do contexto histórico-cultural que se deseja narrar. De modo similar, as análises em torno da família retratada no cinema são orientadas pelo olhar teórico-metodológico que se lança a essas obras, a depender do prisma disciplinar utilizado, como Psicologia, Artes, Comunicação, Sociologia, Filosofia, Antropologia, entre outras. A obra de arte, enquanto recorte e leitura da realidade, interessa ao cientista como todo e qualquer fenômeno humano (Fulgencio, 2013). Sendo assim, considerando essas premissas e amparados no referencial psicanalítico, propomos um olhar para duas obras do cineasta espanhol Pedro Almodóvar Caballero, nascido em 1949.

1 Apoio: CAPES

2 Endereço para correspondência: UFTM, Departamento de Psicologia, Avenida Getúlio Guaritá, 159, $3^{\circ}$ andar, Uberaba - MG, CEP 38025-440.E-mail: scorsolini_usp@yahoo.com.br
A escolha das obras de Pedro Almodóvar é justificada não apenas pelo fato de ele ser, atualmente, o cineasta espanhol de maior renome mundial, como ser o autor de todos os roteiros de seus filmes. Sua filmografia é enriquecida por um acervo de obras nas quais o feminino (não necessariamente personalizado em personagens mulheres) é o ponto principal das tramas, envolto em dramas psicológicos complexos e cenários que privilegiam cores berrantes. Segundo boa parte da crítica especializada, seus filmes são tão autobiográficos quanto poderiam ser, considerando que suas experiências de vida são suas fontes primárias de inspiração. Contemporaneamente, o diretor é tão conhecido quanto seu conterrâneo Luis Buñuel, cineasta influenciado pelo movimento surrealista, cuja obra se assemelha muito ao estilo de Almodóvar.

Volver (2006) e Tudo sobre minha mãe (Todo sobre Mi Madre, 1999) são consideradas duas obras clássicas de Almodóvar. Volver versa sobre três gerações de mulheres que sobrevivem à devastação do vento, ao fogo, à loucura, à superstição e, inclusive, à morte. Essa reafirmação da vida frente às circunstâncias mais extremas acontece com base na bondade das personagens, que não hesitam em recorrer ao recurso da mentira e a uma vitalidade sem limites. As personagens principais do filme são todas mulheres. Raimunda, personagem vivida pela atriz Penélope Cruz, é uma mulher casada, responsável e mãe de uma filha adolescente (Yohana Cobo). O convívio conjugal é permeado por 
relações violentas e incestuosas, que culminam com uma tragédia. Seu marido, Paco, é assassinado, e Raimunda e sua filha tentam se desfazer do corpo sem deixar pistas. $\mathrm{O}$ ato violento, como é usual na cinematografia almodovariana, não é gratuito, mas irrompe como uma decorrência inevitável do colapso psíquico que denuncia a constituição de vínculos opressivos. Nesse contexto, o parricídio, executado pela filha sexualmente abusada, aparece como solução desesperada diante de uma existência que exige o aniquilamento da subjetividade.

Raimunda é uma jovem mãe, bastante trabalhadora e atraente, com um marido desempregado e uma filha em plena adolescência. Para sustentar a família, ela mantém vários empregos. Além disso, guarda um segredo terrível desde sua infância. Sua irmã Sole é um pouco mais velha. Tímida e receosa, ela ganha a vida com um salão de beleza ilegal (não declarado). Seu marido a abandonou e fugiu com uma cliente. Desde então ela vive sozinha. Um dia, Sole telefona para Raimunda para falar que sua tia Paula havia morrido. Raimunda adorava sua tia, mas não pode ir ao funeral porque, momentos antes de receber o telefonema de sua irmã, quando ela acabava de voltar de um de seus empregos, encontrou seu marido morto na cozinha. Sua filha confessa que o matou porque ele havia bebido e tentara abusar dela sexualmente.

A necessidade mais imperiosa para Raimunda é salvar sua filha. Raimunda acoberta o corpo de seu marido, dizendo aos outros que este a abandonara. Ela está tentando se livrar de seu corpo, mas não consegue encontrar um momento propício porque arranjou um novo emprego. Cada uma das duas irmãs vive uma situação inesperada, sobrevivendo a acontecimentos que são intensos, melodramáticos, cômicos e bastante emocionantes. Ambas as mulheres enfrentam tais situações inusitadas com audácia e contando intermináveis mentiras.

Volver é uma história de sobrevivência. Raimunda descobre, ao final da trama, que sua mãe não havia morrido em um incêndio, como se pensava até então, mas que morava com sua tia e cuidava dela, criando uma espécie de fantasma que intrigava Raimunda e sua irmã - e, por extensão, o espectador. No incêndio no qual a mãe de Raimunda supostamente havia morrido, morreram de fato seu pai e sua amante.

Tudo sobre minha mãe (1999) trabalha com a intertextualidade ao resgatar All About Eve (filme de Joseph L. Mankiewicz) e Um Bonde chamado Desejo (peça do dramaturgo norte-americano Tennessee Williams). Esta última se confunde com a história da protagonista do filme, Manuela (Cecília Roth), que decide seguir a atriz principal da peça, Huma (Marisa Paredes), após a morte do filho, o jovem Estéban. Tudo sobre minha mãe é um filme centrado em personagens femininas (Manuela, Huma e Rosa) e feminilizadas, como as travestis Agrado e Estéban/Lola. No passado, Manuela havia se envolvido com uma travesti (Lola), com quem tivera um filho (Estéban). Ao saber que estava grávida, foge para Madrid, onde permanece até a morte do filho, aos 17 anos de idade. Estéban é atropelado ao tentar pedir um autógrafo à atriz Huma (de Um Bonde chamado Desejo), mesma peça que havia sido encenada pelos seus pais no passado e que marcou o início do namoro destes. Manuela nunca havia contado essa história para o filho, que morrera sem saber quem era o seu pai.
Após a morte do filho, Manuela empreende uma viagem de retorno às origens, como parte de seu ritual de elaboração do luto. Volta a Barcelona para procurar Estéban/Lola e contar-lhe a história, da qual ele também havia sido excluído: de que ele era pai e que seu filho varão havia morrido jovem e em circunstâncias trágicas. Mais uma vez, a lente de Almodóvar aponta para o paradoxo existencial: comunica-se ao personagem sua paternidade, o que tem valor de reparação de uma verdade que até então lhe fora negada, e ao mesmo tempo institui-se sua perda, o que torna o trabalho do luto praticamente impossível, pela ausência de inscrição psíquica do objeto perdido. Essa dimensão melancólica, que atravessa o filme de ponta a ponta, será o pano de fundo sobre o qual o cineasta acolhe as vicissitudes da vida.

Por ocasião de seu retorno a Barcelona, Manuela conhece a freira Rosa, que naquele momento acaba de tomar conhecimento de que espera um filho do mesmo homem, Estéban/ Lola. No mesmo ato de reconhecimento de uma verdade tão decisiva, Rosa descobre que é HIV+, em mais um lance de paradoxo existencial que pontua o enredo. Em momento tão delicado de sua vida, pode contar com a solidariedade de Manuela, que assume seus cuidados, utilizando seus conhecimentos de enfermeira. Rosa morre de complicações no parto e, em seu enterro, Manuela finalmente reencontra Estéban/Lola e lhe conta toda a história. O filho de Rosa resiste à morte da mãe e é batizado com o nome do pai, Estéban, por iniciativa de Manuela, que passa a criá-lo. Estéban é o nome verdadeiro de Lola, dado aos seus dois filhos - o filho recém-falecido de Manuela e o filho recém-nascido de Rosa, reativando, assim, o elo da transmissão psíquica. Um elemento importante para contextualizar o título da obra é que Rosa, antes de morrer, pede à Manuela que um dia conte toda a verdade ao seu filho, ou seja, tudo sobre sua mãebem como sobre Estéban/Lola, de modo a quebrar o ciclo de segredos familiares.

Nota-se, assim, que ambas as obras tratam de dramas familiares que envolvem o tênue liame entre a vida e a morte. A morte e a possibilidade de transcendê-la estão personificadas em Paco, em Volver, assim como em Estéban, Estéban/Lola e Rosa em Tudo sobre minha mãe, pari passu com a insistência da vida, que é encarnada nas figuras maternas e nas heranças familiares como fios condutores dos enredos. Nessa vertente compreensiva, o objetivo deste estudo é discutir de que modo a noção de transmissão psíquica está presente nessas duas obras seminais do cineasta espanhol. Pretendemos operar com o conceito de transmissão psíquica transgeracional não apenas como uma ligação conteudística entre as obras e a biografia de Almodóvar, mas como elemento intertextual com as concepções sobre família e transmissão psíquica (Scorsolini-Comin \& Santos, 2012).

\section{Tudo sobre a família: vínculos, laços e conjugalidade}

A partir do olhar da Psicologia, Cicco, Paiva e Gomes (2005) destacam que o estudo da família e dos modelos de relações conjugais em voga na pós-modernidade é um requisito fundamental para a compreensão das mudanças ocorridas nas últimas décadas, bem como de suas implicações 
para o desenvolvimento e amadurecimento dos indivíduos nos contextos familiares atuais. Giddens (1993), ao discutir a transformação da intimidade nas sociedades ocidentais, ressalta que os ideais do amor romântico, relacionados à liberdade individual e à autorrealização, desligam os indivíduos das relações sociais e familiares mais amplas, demarcando com mais clareza a esfera do relacionamento conjugal, que passa a ser, assim, mais valorizada e priorizada. Enfatiza que o amor romântico, desde sua origem, suscita a questão da intimidade e supõe uma comunicação psíquica, um encontro que tem um caráter reparador. $\mathrm{O}$ outro preenche um vazio que o indivíduo, muitas vezes, sequer reconhece; a relação amorosa se instala, e o indivíduo fragmentado sente-se inteiro (Féres-Carneiro, 1998).

Gomes e Paiva (2003), ao investigarem as relações no interior da família e a instituição casamento na perspectiva da virada do milênio, enfocam a percepção das transformações que ocorreram na sociedade pós-moderna, tanto de caráter econômico quanto social e psicológico. Essas autoras revelam que o casamento é sempre visto dentro do contexto familiar, em que a necessidade primordial do casal centrar-se-ia no desejo de "ter filhos", desconsiderando, de certo modo, as questões da própria conjugalidade. Isso pode ser observado em Volver, na personagem de Raimunda. Já em Tudo sobre minha mãe ocorre exatamente o oposto, ou seja, é a gravidez de Manuela que dissolve o casamento, fazendo com que ela fuja do marido por temê-lo ou mesmo por receio de que o filho soubesse que seu pai levava uma vida marginal. A possibilidade de ter de criar o filho ao lado do marido a faz tomar a atitude de assumir sozinha o seu cuidado, sem que o pai sequer tomasse conhecimento da paternidade ou da escolha de sua esposa. Entre as motivações para essa dissolução podemos elencar o fato de Estéban/Lola ser travesti e se prostituir, além do fato de estar envolvido com drogas na época.

Aqui vemos um ponto interessante das escolhas de Manuela: aos seus olhos, Estéban/Lola podia perfeitamente ser um esposo, mesmo tendo comportamentos de risco e uma aparência feminina, porém não poderia ser um bom pai ou transmitir ao filho um legado positivo e proporcionar-lhe uma vida saudável e feliz. O casamento poderia suportar essa situação peculiar e divergente da heteronormatividade, mas não haveria espaço para tal tolerância na parentalidade e na criação do filho. Por outro lado, o dilema ético dessa escolha não passa despercebido da personagem: ao tirar do filho a possibilidade de saber quem era o seu pai, Manuela busca, de certa forma, anular seu legado, embora o filho carregue o nome do pai, Estéban. Esse aparente paradoxo é indicativo da ambivalência dos sentimentos que nutre em relação a Estéban. Uma parcela fundamental da história da origem do filho é suprimida, mas essa parte escamoteada da verdade é recuperada na perpetuação de sua memória por meio do nome próprio, que funciona como chave simbólica para a estruturação identitária do jovem. Por outro lado, a omissão da verdade terá consequências dramáticas, pois é na busca por um nome (um autógrafo da atriz da peça que acabara de assistir) que se dá o trágico e prematuro desfecho da vida de Estebán, o filho. É preciso lembrar que a segunda peça encenada no filme, a tragédia Yerma, do poeta espanhol Garcia Lorca, tematiza a dor de uma mãe. Ambientada na Andaluzia, no início do século XX, conta a história de Yerma, uma mulher que vive o drama de não poder conceber um filho. A personagem busca de todas as maneiras engravidar e enfrenta a indiferença de Juan, seu marido. Desespera-se ao descobrir que Juan, na verdade, não deseja ter filhos e, ensandecida entre o desejo de conceber e a percepção de sua impossibilidade, Yerma estrangula o marido. $\mathrm{O}$ mote principal da peça pode ser assim resumido: uma mulher se casa com o homem errado e por essa paixão terá de sofrer durante toda sua vida.

Atualmente, concebe-se que o casamento pode ser um espaço de desenvolvimento das individualidades, na medida em que é um processo de individuação entre os parceiros (Féres-Carneiro, 1998; Gomes \& Paiva, 2003). Alguns estudos partem da noção de que o self não pode se desenvolver no isolamento e de que o eu é definido pela sua diferenciação com o tu, de modo que o tu dá a base para a identidade do indivíduo, desde que se possam diferenciar dois processos importantes presentes nas relações conjugais: a intimidade e a fusão. Sendo assim, Féres-Carneiro (1998) descreve como o casal contemporâneo é confrontado por duas forças paradoxais, ou seja, pelas tensões entre individualidade e conjugalidade. Para esta autora, o desafio de um casal reside, fundamentalmente, no fato de o casamento ou união ser um palco no qual devem se entrelaçar as individualidades de cada membro, operando-se a construção de um lugar em comum, o que a autora define como conjugalidade. Em Tudo sobre minha mãe, a individualização do casal é representada pela própria transformação de Estéban em Lola, o que ocorre em um período no qual o casal está separado - Manuela está, portanto, distante do esposo. Quando Manuela decide retornar, encontra o marido totalmente transformado, agora vivendo como uma travesti, após completar seu processo de transição para a identidade feminina. Manuela descobre que Stebán faz programas próximo da casa onde moravam. Mesmo chocada com a situação, Manuela perdoa o esposo pelo ocorrido e busca se redimir do passado. Nesse processo de transformação de si própria, passa a aceitá-lo, embora não mais vivam juntos. Assim, uma nova conjugalidade passa a ser constituída, até o momento em que ela engravida e resolve se mudar com o filho. Manuela parece não suportar o impacto de permanecer frente ao desconhecido, simbolicamente representado pelo filho que cresce em seu ventre.

Este modelo único que cada par cria, com suas afetividades, seus acordos e suas heranças psíquicas, é denominado "absoluto do casal", conceito que determina os seus limites, ou seja, concebe o casal como uma entidade composta por duas pessoas e o seu modelo único. Para Féres-Carneiro (1998), esse conceito recebe o nome de identidade conjugal, o que na literatura específica é designado como conjugalidade (Caillé, 1991; Cicco et al., 2005; Diniz-Neto \& Féres-Carneiro, 2005; Magalhães \& Féres-Carneiro, 2007). A conjugalidade, assim como pode ser construída, pode ser dissolvida, como observamos em Volver. Na trama de maior impacto desse filme, a filha mata o pai, em um gesto desesperado de autodefesa, quando ele tentava abusar sexualmente dela. Já em Tudo sobre minha mãe a esposa abandona o marido assim que descobre que está grávida, privando-o da possibilidade de conhecer o filho e seu status de pai. Vemos que nos dois casos a conjugalidade é dissolvida não por uma dinâmica interna do casamento (os filmes 
não abordam suficientemente, mas sugerem que os casais estavam insatisfeitos) ou deliberação de ambos os cônjuges (Manuela não abandonou seu marido quando descobriu que ele se travestia e se prostituía, mas sim quando engravidou). O que rege a dissolução do vínculo conjugal são situações externas à relação e ao casamento em si, mas que acabam incidindo sobre ele, fazendo-o desmoronar.

A conjugalidade se dilui em Volver pelo fato de o marido ter traído a esposa e ter tentado abusar da filha, o que mostra que a dimensão familiar acaba se sobrepondo à do casamento. A figura do marido acaba sendo concebida como uma presença inconveniente que precisa ser afastada ou exterminada, como se devesse ser punido pelo ato incestuoso que estava prestes a praticar (embora seu potencial traumático jamais possa ser apagado da vida da mãe e da filha), motivo pelo qual ele é morto e seu cadáver é carregado pela esposa e armazenado em um congelador, à espera de uma oportunidade para enterrá-lo sem levantar suspeitas do ato criminoso praticado. A relação que permanece é a da maternidade - cúmplice, solidária à dor da filha, e não a da conjugalidade. Como a relação conjugal já estava absolutamente corroída e desgastada, a ameaça de perpetuação do estupro e do incesto funcionou apenas como a gota d'água, que finalmente se converteu na pá de cal que sepultou de vez um relacionamento que entrara em colapso. O que motiva Raimunda a reagir como uma leoa que protege sua cria também foi o fato de que ali se repetira a história trágica de sua própria adolescência - algo que o espectador toma conhecimento só depois. Raimunda experimentara algo semelhante em sua adolescência, por isso ela sente alívio ao saber que a filha, em defesa de sua integridade, conseguiu quebrar o ciclo transgeracional de violência perpetrada pelo parceiro íntimo em relação ao qual ela, Raimunda, tinha ficado subjugada.

No outro filme, o mesmo movimento de dissolução pode ser observado, na medida em que a protagonista, para preservar a família que estava sendo reconstituída, agora pelo anúncio da chegada do filho, acaba terminando seu relacionamento como forma de preservar a criança do contato com o pai, travesti envolvida com drogas e prostituição. Isso mostra que o preconceito e a transfobia estavam internalizados em Manuela, embora ela não tivesse consciência dessa injunção. Aqui vemos o propósito de uma mãe que busca "salvar" o filho do que ela provavelmente considerava uma má influência ou sentença de infortúnio e sofrimento para um infante. Ao longo de sua vida, o filho declara insistentemente à mãe que gostaria de conhecer a história do pai, qualquer que fosse. É um clamor pungente que, no entanto, não chega a mudar a firme convicção de Manuela e sua obstinada luta pela não integração da verdade suprimida acerca da origem do filho. Na verdade, do ponto de vista do filho, é também a história da mãe que lhe é suprimida, pois é por não querer contar a sua própria história de envolvimento amoroso que a mãe resiste em revelar-lhe a identidade do pai, Estéban/Lola.

Em Tudo sobre minha mãe as profundas transformações por que passa a família são vistas como um processo que envolve um segredo familiar. O filme retrata uma família chefiada por uma mulher que abandonou o marido. A história familiar não é apresentada ao próprio filho, Estéban, como se este tivesse apenas mãe. A conjugalidade de seus pais não apenas é omitida, como também é negada por Manuela, que havia rasgado todas as fotos do ex-marido. O motivo de tal dissolução fora o fato de Estéban (pai) ter se transformado em Lola, após ter permanecido um tempo longe da mulher. Ainda assim, após tomar conhecimento dessa mudança radical, Manuela decide continuar com seu esposo, só o abandonando ao saber que estava grávida. As origens do pai não são reveladas ao filho, que cresce sem saber também quem era, de fato, a sua mãe. Isso o faz mergulhar em uma existência fragmentada, que ele busca tratar em termos da busca do pedaço que falta na vida da mãe e também na sua - o mesmo pedaço (Estéban/Lola, de quem ele carrega o primeiro nome, que por outro lado oculta o segundo, a face renegada do pai). Esse é o ponto no qual ele consolida sua identificação com a mãe e no qual ele permanece alienado e estagnado, já que sua não resolução o impede de aceder à constituição de sua própria identidade e individualidade.

Um novo espaço familiar é criado no filme quando Manuela, já em processo de luto pela perda do filho, vai em busca de Estéban/Lola disposta a restituir finalmente a verdade suprimida e no caminho se depara com a freira Rosa, que também estava esperando um filho deste. Como parte de seu ritual de luto e impelida por um impulso reparador, Manuela passa a cuidar de Rosa, fragilizada pela gravidez e pela doença. A relação afetuosa e solidária que se estabelece entre as duas mulheres sela o pacto pela vida, representada no novo que estava prestes a nascer. Essa situação inusitada abre a oportunidade para Manuela se reposicionar em relação à atitude que assumira no passado, quando fugiu por não suportar gerir o novo, simbolizado pela gestação. Agora, mesmo sob condições mais adversas, ela resolve permanecer e cuidar da mãe que vive em profundo desamparo - afinal, além de ter infringido seus votos como freira, se contaminara por uma doença sexualmente transmissível. Desse modo, as duas mulheres acabam constituindo um núcleo familiar cujo elo é (sempre ele!) Estéban/Lola, ex-marido de Manuela e pai de seu filho, e agora também pai do filho de Rosa. O que Estéban, o elemento masculino, inocula e transmite é, simultaneamente, vida e morte. O que Manuela, Rosa (e Lola), elementos femininos da trama, concentram é o dom de receber a vida e a obstinação de preservá-la a todo custo, mesmo em condições penosas. Quando Rosa morre no parto, é Manuela quem assume os cuidados de seu filho, também batizado com o nome Estéban. Sendo assim, vemos o traço transgeracional marcado no significante Estéban, que insiste em permanecer após duas mortes (do filho e do pai) e o retorno a um núcleo familiar chefiado, mais uma vez, por uma mulher.

Em Volver, Raimunda vê-se obrigada a assumir a autoria do crime, uma vez que não poderia deixar que sua filha fosse presa. Raimunda entende que o assassinato (parricídio) havia sido "justo", um castigo merecido por ele ter tentado assediar a própria filha. Há nisso uma ideia de valor primordial, que antecede à própria moral dos homens. A morte do pai pelas mãos da própria filha encerra uma situação de violência intrafamiliar e de desintegração dos laços sociais. Tal deterioração culmina na morte do pai, o que não termina com a saga da família, que agora passa a esconder o corpo do pai e a inventar que o mesmo havia sumido, abandonando o 
lar. Nota-se aqui a recorrência da temática da manutenção do segredo às custas de um apagamento brutal da história familiar. A nova família passa a ser constituída apenas por mãe e filha, que vão morar com a tia (Sole), na tentativa de recomeçar a vida. Nessa nova configuração familiar, há apenas personagens femininas, o que indicia a figura materna como condutora das tramas, dos destinos e dos enredos vividos por essas mulheres. $\mathrm{O}$ elemento masculino é quase totalmente apagado, como se fosse um traço facilmente extirpável, pois era uma fonte de sofrimento psíquico para todas as mulheres da trama, traídas por seus maridos e obrigadas a mudarem de vida por conta disso.

Wagner e Falcke (2001) elaboraram uma revisão da literatura da área de família, cotejando os estudos publicados na última década do século XX que abrangiam várias correntes teóricas da Psicologia e nos quais os pesquisadores se dedicaram a examinar a influência da família de origem nas escolhas conjugais e na determinação dos motivos (conscientes e inconscientes) que levam as pessoas a elegerem seus parceiros. As autoras confirmaram a existência de uma forte tendência à repetição de padrões de relacionamentos afetivos experimentados na infância e colocaram em destaque a reprodução de padrões destrutivos aprendidos nas famílias de origem. Em Tudo sobre minha mãe, a reiteração desses padrões de violência intrafamiliar gira em torno da personagem de Estéban/Lola. Como profissional do sexo, em seu trabalho como travesti que se prostitui, afasta-se de um ideal masculino associado à figura de pai, um dos motivos que torna a deflagração do mistério de quem é este pai coadjuvante em relação à Manuela, mãe e mulher que liga sua história à de Rosa. O título do filme Tudo sobre minha mãe não deixa dúvidas sobre quem é a referência na construção da posição identitária. Por outro lado, o malogro do projeto existencial de Manuela indica, sem disfarce, a impossibilidade de compreendermos tudo sobre o outro, já que algo sempre nos escapa no momento mesmo em que imaginamos que o apreendemos em sua verdade, sugerindo, assim, a falácia da pretensão à totalidade.

\section{Volver o passado: o processo de transmissão psíquica}

O primeiro indício proposto pelo filme Volver está involucrado em seu próprio título, que significa retornar a um lugar onde se esteve anteriormente, podendo ser compreendido também como o remexer (revolver) de lembranças, histórias e fantasias. Tais sentidos possíveis estão na base do conceito de transmissão psíquica, como veremos a seguir. Diversos autores, como Eiguer (1984), Lemaire (1988) e Nicollò (1988), assinalam que a conjugalidade, ao mesmo tempo em que reedita o romance familiar, propicia a elaboração das vivências infantis.

$\mathrm{O}$ encontro com o parceiro gera a oportunidade de reparação, elaboração e desenvolvimento do psiquismo, entrelaçando passado e presente dentro de um projeto que pressupõe uma perspectiva de futuro a dois. Desde o momento da concepção, o sujeito está marcado pelo olhar dos pais, pelos seus ideais e pelos mitos familiares que se inscrevem e estruturam o psiquismo. Enovelado nessa malha de significantes, o bebê retoma e encarna o ideal narcísico dos pais e, ao mesmo tempo, se alimenta desse envoltório narcísico para se constituir como sujeito e, em um futuro provável, constituir novas conjugalidades e dar prosseguimento à sua descendência.

Desse modo, a família teria um papel fundamental como intermediária no processo de transmissão psíquica, realçando as possibilidades de transformação inerentes ao ato de transmitir e permitindo a construção da subjetivação (Magalhães \& Féres-Carneiro, 2007; Ziviani, Féres-Carneiro, \& Magalhães, 2012). O engendramento de processos de subjetivação é permitido, em Tudo sobre minha mãe, não por um núcleo familiar constituído, mas pelo legado paterno que atravessa, como um ginete, a história dos dois Estéban. Ainda que eles tenham mães diferentes, são signos de continuidade: o filho de Manuela que morrera e o filho de Rosa, que acabara de nascer.

Segundo Gomes (2005), a transmissão psíquica geracional se apresenta de duas formas distintas: 1) a intergeracio$n a l$, que é aquela que inclui um espaço de metabolização do material psíquico transmitido pela geração mais próxima e que, transformado, passará à seguinte; e 2), a transgeracional, que se refere a um material psíquico da herança genealógica não-transformada e não-simbolizada, apresentando, assim, vazios e lacunas na transmissão, de modo que o significado velado aponta para o fato psíquico inconsciente que atravessa diversas gerações.

O fato psíquico inconsciente, em Tudo sobre minha mãe, é a travestilidade do pai e a incidência de suas significações sobre a figura paterna e a repercussão dessa transgressão no ser feminino de Manuela e Rosa. Ambas são mulheres fertilizadas por um homem que se prostitui com outros homens e que marca ostensivamente, na superfície de seu corpo, sua feminilidade emblemática: os cabelos e o rosto expressivos, a maquiagem carregada, o vestido apertado delineando os seios fartos. O que Manuela e Rosa parecem não poder suportar e simbolizar é o fato de se envolverem com uma travesti, que não se torna apenas marido, mas pai de seus filhos e motivo de vergonha e angústia para elas. A diferença elaborada entre essas duas gerações é o fato de que Manuela esconde do filho o segredo do pai e Rosa faz questão de que o filho saiba "tudo sobre sua mãe" - conforme seu derradeiro pedido no leito de morte, ainda que o segredo esteja novamente guardado por Manuela, que é especialista nessa tarefa. Fica no ar a dúvida: no futuro, Manuela cumprirá a promessa que fez à Rosa, vendo nessa situação uma oportunidade ideal para reparar o mal que fizera ao próprio filho, ao ocultar-lhe a verdade? Almodóvar prefere deixar a situação em suspenso, apenas sugerida, mantendo seu desfecho em aberto.

A noção de transmissão psíquica geracional se refere à inscrição do sujeito na cadeia da qual ele é um elo e, ao mesmo tempo, à qual ele se submete; concerne à estruturação da subjetividade, ao desenvolvimento psíquico daquilo que o sujeito herda, ao seu pertencimento ao grupo familiar e às formações intermediárias que articulam os espaços psíquicos intra e intersubjetivos. Kaës (1998) ressalta que a transmissão geracional implica a precedência do sujeito por mais de um outro e a forma como ele lida com a herança, sendo também cuidador, pensador e até criador daquilo que foi transmitido. Nesse sentido, Almodóvar deixa ao espectador o trabalho de responder a pergunta: o que será que vai acontecer àquele 
bebê no futuro, após o destino ter restituído a Manuela o direito de repetir ou retificar sua escolha anterior de suprimir a verdade da origem do filho?

Kaës (1998) afirma que a genealogia mistura tempos e espaços, podendo desencadear repetições, padrões estereotipados que cristalizam psicopatologias ou, pelo contrário, gerar elaborações criativas e inovadoras. Assim como a família e o casal, o sujeito tem como tarefa construir, organizar e transfigurar suas heranças, elaborando o legado que recebe, para que possa transmiti-lo com sua marca transformadora. Ou seja, com sua marca autoral, porque só assim a pessoa conseguirá imprimir sua assinatura na própria história, tornando-se protagonista de seu devir.

\section{A parentalidade como um bonde que atravessa a vida}

Para Bertin e Passos (2003), com o nascimento dos filhos, o casal estrutura um grupo familiar, responsável pela escritura dos enredos que serão protagonizados pelas gerações que os sucederem. Quando o casal também não organiza o enredo e as heranças que serão transmitidas (é o caso de Manuela, cujo marido nem sabia que era pai), o responsável pela transmissão pode ser um dos membros do casal (no caso, a mãe). É ela quem, escamoteando a identidade do pai, acaba não elaborando a sua própria condição de mulher casada com uma travesti, o que a leva a conhecer Rosa, que também se envolvera com Estéban/ Lola. Assim, Manuela busca, de certo modo, reencontrar-se com sua própria história de rejeição da dualidade sexual ao encontrar-se com a história de Rosa. Ela claramente escolhe esse caminho, pois poderia perfeitamente se manter afastada de Rosa e deixá-la ter seu filho solitariamente, como, aliás, Manuela havia feito por opção própria no passado. Ao não fazê-lo, Manuela rompe com a repetição de um padrão de resolução de conflito. Não se sabe se por culpa ou para tentar elaborar sua própria dor de mãe e de esposa, Manuela acaba trilhando com Rosa cada passo de sua gestação, tornando-se pouco depois mãe do terceiro Estéban do filme, o filho de Rosa e Estéban/Lola.

O desenvolvimento desses enredos cíclicos pressupõe investimentos recíprocos dos membros do grupo, que continuarão a existir enquanto a criança prover suas expectativas de continuidade. Assim, pertencer a uma família, ou seja, ser considerado suporte de um discurso, oferece ao aparelho psíquico em vias de formação um alicerce, uma verdade inicial que sustenta o ingresso do sujeito na história. Esta, por sua vez, gera a vivência de ser amado e reconhecido, e de ocupar um lugar em um mundo que o precede e o espera. Este lugar já é esperado por Estéban, que nasce órfão de pai (Estéban/ Lola morre logo em seguida) e mãe (Rosa morre no parto) e é criado por Manuela, que tinha uma história semelhante à de sua mãe biológica. Assim, as histórias dessas duas mulheres não apenas se mesclam como se identificam, se confundem e se reconfiguram na criação do terceiro Estéban, que já nasce predestinado a ser autor de uma história original e, para tanto, não poderá se deixar levar pela tendência inercial de re-petir, isto é, de pedir mais do mesmo. Para quebrar esse fado, deverá futuramente descobrir tudo sobre suas duas mães, Rosa e
Manuela. Nota-se, assim, na linha de transmissão psíquica, que a geração futura está fadada a ajustar contas com tarefas que as anteriores não deram conta de solucionar (Benghozi, 2010; Valdanha, Scorsolini-Comin, \& Santos, 2013).

É importante destacar que a escolha do nome Estéban partiu de Rosa, como uma forma de prestar uma homenagem ao filho de Manuela, prematuramente morto em um acidente. A escolha de Manuela como tutora do filho também havia sido feita por Rosa antes do parto: caso "alguma coisa acontecesse", Manuela deveria cuidar de seu filho, o que acaba se concretizando. A família de Rosa pouco participa desse processo, uma vez que a criança nasce soropositiva e a avó, figura extremamente controladora, teme ser contaminada. $\mathrm{O}$ avô está demenciado e não se lembra de ter uma filha, quanto mais um neto. É também em função dessa configuração familiar precária que Rosa, quando descobre estar grávida, busca a ajuda de Manuela, a quem acabara de conhecer, ao invés de sua família. Esse gesto evoca a situação da personagem Blanche DuBois, protagonista de Um Bonde chamado Desejo, que ao final da peça conclui que sempre dependeu da bondade de estranhos.

Bertin e Passos (2003) concluem que, no trabalho de transmissão que opera na sucessão de gerações, cada família transfere sua forma de entender e apreender o mundo externo, assim como de organizar o mundo interno. É a partir desses dispositivos psíquicos que a criança, por meio de suas interpretações, erigirá seu mundo interno, enriquecido por suas próprias fantasias. Na gênese do mundo interno do sujeito é preciso considerar também uma dimensão intragrupal, atual, e uma dimensão histórica, constituída a partir do trabalho acumulado de sucessivas gerações. Para Whitaker (1989), a relação de casal teria o valor de produzir profundas e necessárias modificações psíquicas nas pessoas, notadamente porque permite a experiência nova de ingressar na família de origem do parceiro. Esse encontro com a alteridade, no bojo da exogamia, atuaria como elemento diferenciador do psiquismo.

A partir das questões de transgeracionalidade, Wagner e Falcke (2001) destacam que a formação do casal e, consequentemente, de uma nova família, se dá por meio do encontro dos sistemas de crenças das famílias de origem dos cônjuges. Assim, quando as pessoas se casam ou passam a viver em união conjugal, acontece o encaixe entre sistemas míticos de duas estruturas familiares diferentes, formando um novo sistema baseado nos sistemas familiares de cada cônjuge. As autoras sugerem, então, que o casamento ou união constitui-se em um processo que não é exclusivo do noivo e da noiva, ou do homem e da mulher. Ao contrário, "nele estão implicadas fortemente as famílias de origem de cada cônjuge, como transmissoras de um sistema mítico que precisa ser examinado e devidamente considerado na formação do casal" (Wagner \& Falcke, 2001, p. 5).

Volver mostra claramente duas irmãs (Raimunda e Sole) traídas pelos maridos, assim como acontecera com sua mãe. Além disso, essas três mulheres compartilham não apenas casamentos frustrados, mas desfechos trágicos desses relacionamentos - o pai de Sole e Raimunda morre em um incêndio e o marido de Raimunda é assassinado pela filha. As mentiras criadas por Raimunda e sua mãe acabam acobertando a morte de Paco (esposo de Raimunda, cujo corpo é carregado por ela 
clandestinamente) e também da própria mãe da protagonista, que resolve se esconder, doravante passando-se por um fantasma, de modo a não ter que enfrentar a cáustica realidade da traição, da morte do esposo e de seu amante, e olhar de frente sua própria vida. Raimunda, mesmo desconhecendo o destino de sua mãe, acaba repetindo sua trajetória - note-se, aqui, as famílias de origem de cada cônjuge, como transmissoras de um sistema mítico, escondendo-se dos fatos reais como a morte do marido e a autoria do crime imputada à sua filha. Tal repetição não ocorre ao acaso, mas quando Raimunda volta à sua cidade natal - uma viagem com ressonância mítica - é como se ela retornasse não apenas para elaborar a morte do marido e o crime que estava acobertando, mas revisitando sua própria história, revolvendo a pátina que encobria sua origem e sua ligação primitiva com sua mãe.

\section{Quase tudo sobre o casamento: as escolhas amorosas e a transmissão psíquica}

Diferentes pesquisadores da Psicologia estudaram a influência da família de origem nas escolhas conjugais e na determinação dos motivos que levam as pessoas a elegerem um(a) ou outro(a) parceiro(a), quer no casamento ou em uniões do tipo namoro. Sendo por motivações conscientes ou inconscientes, em decorrência da introjeção dos modelos parentais ou pela repetição de padrões familiares, a importância das experiências com a família de origem é um fenômeno frequentemente considerado como a base dessa escolha (Wagner \& Falcke, 2001). Verifica-se, a partir das considerações das autoras, que a atração amorosa e sexual, o estabelecimento de vínculos afetivos, bem como as demais características das alianças estabelecidas entre os partícipes do casal, provavelmente estejam subordinados às influências dos sistemas familiares nos quais se formaram e estão inseridos ambos os parceiros. Isso pode ser ilustrado pelas escolhas amorosas de Sole e Raimunda, em Volver, que se envolvem com homens que as traem e as fazem infelizes, como seu pai em relação à sua mãe. Assim, elas repetem a escolha feita pela mãe na tentativa de reelaborar não apenas a necessidade de estar ao lado de homens com esse perfil, mas também de mudarem de vida ao serem abandonadas ou abandonarem esses homens.

Para Cruz (2005), as emoções parentais funcionam como uma espécie de barômetro, refletindo a qualidade do ambiente familiar. Mais do que isso, aponta-se que o afeto parental positivo prediz consistentemente resultados de desenvolvimentos favoráveis na criança e no adolescente futuramente, enquanto a hostilidade parental está relacionada com resultados desenvolvimentais desfavoráveis. Pode-se observar então que, além da tendência de repetição dos padrões de relacionamento aprendidos, o casamento dos pais também pode ser considerado o modelo de relação conjugal que as pessoas tomam como fundamento de suas relações amorosas. O estudo da satisfação conjugal deve se colocar diante dessas considerações, abarcando essa dimensão constitutiva. Nesse sentido, cada cônjuge traz para o casamento tanto um modelo de interação aprendido, como também expectativas baseadas no que observou na relação de casal de seus pais. A partir dessas observações, podem buscar relacionamentos similares quando aprovaram o que viram, ou muito diferentes, quando desaprovaram.

Pensando especificamente na satisfação encontrada nos relacionamentos afetivos, as autoras destacam que dificilmente um casal poderá estabelecer uma relação afetiva e sexualmente feliz se não tiver conseguido uma boa independização dos pais e a consolidado nos primeiros anos de relacionamento conjugal. Salientam, entretanto, que como ninguém se separa totalmente de sua família de origem - vide as escolhas de Raimunda e Sole, em Volver, e as de Manuela, em Tudo sobre minha mãe, por mais independente que seja, tanto emocional como economicamente, a atitude madura é caracterizada pela capacidade de evitar que as famílias de ambos os cônjuges entrem em conflito, preservando o bom relacionamento entre ambas. Nesse sentido, é fundamental que exista o respeito pela família e os valores do outro.

\section{Considerações Finais}

Tendo a transmissão psíquica como norte, Wagner e Falcke (2001) buscaram conhecer quais as implicações das experiências familiares na vida afetiva dos indivíduos. Nos diversos estudos analisados, observaram-se abundantes registros que enfatizam a importância das experiências na família de origem como determinante da escolha e, consequentemente, da satisfação conjugal. Atribui-se essa importância ao fato de que, ao longo da vida, os sujeitos acabam repetindo o padrão de relacionamento que experimentaram na relação pais e filhos, assim como tomam também como base aquilo que observaram do relacionamento conjugal de seus pais. Desse modo, a família ocuparia uma posição central em nossas escolhas amorosas.

Em Tudo sobre minha mãe não temos dados sobre a escolha amorosa de Manuela por Estéban/Lola, mas podemos presumir que esta se consolidou quando este ainda era simplesmente Estéban. Manuela é levada a viver novamente uma situação semelhante ao encontrar-se com Rosa, também grávida de Estéban/Lola. Desse modo, sua herança consiste em elaborar não apenas o amor ferido por Estéban/Lola, como a maternidade solitária pelo fato de não aceitar dar ao filho um pai que leva uma vida de travesti. O filme lança alguns indícios de que essa condição ambígua de Estéban/ Lola não era a única a impedir sua ascensão à paternidade, mas o fato de se prostituir, de se envolver com drogas, de ser soropositivo e ter comportamentos agressivos e autodestrutivos. Mesmo envolto por essa imagem negativa, seu nome de batismo é herdado pelo filho de Manuela, seu primogênito, e mais tarde pelo de Rosa - também em homenagem à memória do filho de Manuela, que falecera havia poucos meses. O nome Estéban é uma herança que revela um lugar, um posicionamento e uma história de vida que se deseja, ainda que, inconscientemente, transmitir. As heranças podem ser negadas, mas continuam a existir no psiquismo. O nome que os filhos carregam não apenas deflagra sua referência a uma paternidade problemática, como também os situa em relação a uma origem, um passado do qual não se pode abdicar, mas sim assumir, de um modo ou de outro.

E por que essas mulheres se sentiam atraídas por um homem com essas características? Em que essa escolha amo- 
rosa fala do modo como se posicionam frente ao enigma dos sexos? Tal motivação não é solucionada pelo filme, embora a repetição da situação revele a Manuela a necessidade de encarar sua própria história com verdade, assumindo-a em todos os seus capítulos, em vez de deixar páginas em branco. A lacuna que precisava ser elaborada não era sua paixão por uma figura que funde o masculino e o feminino, mas sua dificuldade em lidar com essa posição amorosa quando se tornara mãe. Tal como Um bonde chamado desejo, outra obra resgatada em Tudo sobre minha mãe, a história de uma mulher que engravida e foge do marido é encarada como uma condição que transforma a vida das personagens principais que, por sua vez, transmutam também a existência das demais pessoas com quem ela se envolve.

Em uma das passagens finais do filme, Manuela explica a Huma, protagonista de Um bonde chamado desejo, que essa peça do dramaturgo Tennessee Williams havia atravessado toda sua vida e fazia parte de sua trajetória pessoal desde o momento em que conhecera seu esposo (Estéban) em um grupo de teatro amador, até a morte de seu filho, que morrera atropelado tentando conseguir um autógrafo de Huma. O bonde que atravessa a vida de Manuela pode ser entendido como o seu desejo por Estéban, potencialmente disruptivo e transgressivo como a paixão crua que a personagem da peça, Blanche DuBois, nutria por Stanley Kowalski, seu cunhado truculento. O relacionamento tenso e áspero chega ao ponto máximo de exasperação quando Blanche é brutalmente estuprada por Stanley. No desfecho da peça, consumida pela paixão reprimida, Blanche termina sendo arrastada, à revelia de sua vontade, para o manicômio.

Já em Manuela, a paixão assume um outro diapasão, ao ser mitigada no amor e virar oferta generosa de si para o outro. Por isso é capaz de perdoar Estéban por ter se transformado em Lola, mas não por ter se destruído com a prostituição e a dependência química. $\mathrm{O}$ desejo que atravessa e incendeia a vida de Manuela também alcança Rosa, que abandona o voto de castidade para mergulhar de cabeça nesse sentimento enlouquecedor, como um bonde que atravessa suas histórias e as atropela, as mata e as faz reviver para elaborarem o material psíquico ainda pulsante que ainda não se consumiu. Desse modo, Almodóvar utiliza fartamente do recurso da intertextualidade - no caso, com a peça de Tennessee Williams - para mostrar como um mesmo elemento não elaborado pode atravessar e marcar a vida dessas personagens, ligadas pela arte e pela obsessão por um homem/mulher. Desejo bifronte, portanto, ao trazer para o primeiro plano a bissexualidade constitutiva da condição humana.

Volver é uma história completamente inserida na dinâmica da transmissão psíquica, na medida em que não apenas as personagens femininas estão vinculadas intimamente pela repetição de um mesmo padrão de relacionamento: casam-se com homens infiéis e sustentam casamentos que são fontes de sofrimento e desconforto emocional. Além disso, o componente morte-vida permeia a história de Raimunda e sua mãe, na medida em que ambas se dedicam a ocultar cadáveres: Raimunda esconde a morte do marido e a sua mãe esconde a sua própria vida, fingindo-se de morta. A morte (real ou fictícia) dessas personagens é revelada como algo importante para solucionar problemas e também como uma tentativa de apagar o passado e as vivências familiares traumáticas. No entanto, essas duas mentiras acabam sendo desveladas, destacando-se não apenas a morte de Paco, como a sobrevivência de sua mãe, o que podemos interpretar como a sobrevivência fantasmática de seu passado não elaborado e ainda latente.

Conclui-se que a temática da transmissão psíquica, enquanto componente exaustivamente trabalhado na obra cinematográfica de Almodóvar, notadamente nas duas produções analisadas, revela não apenas repetições e reelaborações de materiais psíquicos latentes das personagens, mas também de histórias que ainda se encontram por fazer, uma vez que suas tramas não possuem um desfecho conclusivo, mas um fim possível, aberto a outros eventos e vivências, como ocorre na realidade. A transmissão deflagra a necessidade de que esses elementos (mortes, nascimentos, alegrias, rancores, desejos, escolhas, traições, percursos de vida) não apenas sejam elaborados, como possibilitem - no cinema, nas obras de arte ou na vida concreta de seus protagonistas - releituras das trajetórias que os colocam em novas perspectivas, que se cruzam em níveis material e psíquico, estabelecendo, do ponto de vista da estruturação dos papéis familiares, limites claros entre as gerações, em vez de limites difusos e perturbados.

\section{Referências}

Almodóvar, P. (1999). Todo sobre mi madre [longa-metragem]. Espanha: El Deseo S. A.

Almodóvar, P. (2006). Volver [longa-metragem]. Espanha: El Deseo S. A.

Benghozi, P. (2010). Malhagem, filiação e afiliação - Psicanálise dos vínculos: Casal, família, grupo, instituição e campo social. (E. D. Galery, Trad.). São Paulo: Vetor.

Bertin, I. P., \& Passos, M. C. (2003). A transmissão psíquica em debate: Breve roteiro das concepções psicanalítica e sistêmica. Interações, 8(15), 65-79.

Caillé, P. (1991). Un et un font trois: Le couple révélé à lui-même. Paris: ESF.

Cicco, M. F., Paiva, M. L., \& Gomes, I. C. (2005). Família e conjugalidade: o sintoma dos filhos frente à imaturidade do casal parental. Psicologia Clínica, 17(2), 53-63.

Cruz, O. (2005). Parentalidade. Coimbra: Quarteto.

Diniz-Neto, O., \& Féres-Carneiro, T. (2005). Psicoterapia de casal na pós-modernidade: Rupturas e possibilidades. Estudos de Psicologia, 22(2), 133-141.

Eiguer, A. (1984). La thérapie psychoanalitique de couple. Paris: Dunod.

Féres-Carneiro, T. (1998). Casamento contemporâneo: O difícil convívio da individualidade com a conjugalidade. Psicologia: Reflexão e Crítica, 11(2), 379-394.

Fulgencio, L. (2013). Metodologia de pesquisa em psicanálise na universidade. In C. A. Serralha, \& F. Scorsolini-Comin (Eds.), Psicanálise e universidade: Um encontro na pesquisa (pp. 25-66). Curitiba: CRV.

Giddens, A. (1993). Transformações da intimidade: Sexualidade, amor e erotismo nas sociedades modernas. (M. Lopes, Trad.). São Paulo: Editora UNESP.

Gomes, I. C. (2005). Transmissão psíquica transgeracional e violência conjugal: Um relato de caso. Boletim de Psicologia, 55(123), 177-188. 
Gomes, I. C., \& Paiva, M. L. S. C. (2003). Casamento e família no século XXI: Possibilidade de holding? Psicologia em Estudo, 8(número especial), 3-9.

Kaës, R. (1998). Os dispositivos psicanalíticos e as incidências da geração. In A. Eiguer (Ed.), A transmissão do psiquismo entre gerações (pp. 55-19). São Paulo: Unimarco.

Lemaire, J. (1988). Du je au nous, ou du nous au je? Il n'y a pas de sujet tout constitué. Dialogue: recherches cliniques et sociologiques sur le couple et la famille, 102(4), 72-79.

Magalhães, A. S., \& Féres-Carneiro, T. (2007). Transmissão psíquica geracional: Um estudo de caso. In T. Féres-Carneiro (Ed.), Família e casal: Saúde, trabalho e modos de vinculação (pp. 341-364). São Paulo: Casa do Psicólogo.

Mankiewicz, J. L. (1950). All about Eve [longa-metragem]. EUA: Twentieth Century-Fox Film Corporation.

Moellmann, A. (2007). Autorretrato de um sonhador: Cinema, inadequação e melancolia. Dissertação de Mestrado nãopublicada, Faculdade de Educação, Universidade de Brasília, Brasília, DF.

Nicollò, A. M. (1988). Soigner à l'intérieur de l'autre: Notes sur la dynamique entre l'individu et la famille. Rome: Mimeo.

Scorsolini-Comin, F., \& Santos, M. A. (2012). Família interdita: Transgeracionalidade e subjetivação em três obras ficcionais. Psicologia em Estudo, 17(2), 255-266.
Valdanha, E. D., Scorsolini-Comin, F., \& Santos, M. A. (2013). Anorexia nervosa e transmissão psíquica transgeracional. Revista Latinoamericana de Psicopatologia Fundamental, 16(1), 71-88.

Wagner, A., \& Falcke, D. (2001). Satisfação conjugal e transgeracionalidade: Uma revisão teórica sobre o tema. Psicologia Clínica, 13(2), 1-15.

Whitaker, C. A. (1989). Considerazioni notturne di un terapeuta della famiglia. Roma: Astrolabio.

Williams, T. (1947). A streetcar named desire [peça teatral]. EUA.

Ziviani, C., Féres-Carneiro, T., \& Magalhães, A. S. (2012). Pai e mãe na conjugalidade: Aspectos conceituais e validação de construto. Paidéia (Ribeirão Preto), 22(52), 165-176.

Recebido em 02.07.2010

Primeira decisão editorial em 06.05.2013

Versão final em 06.05.2013

Aceito em 06.05.2013 